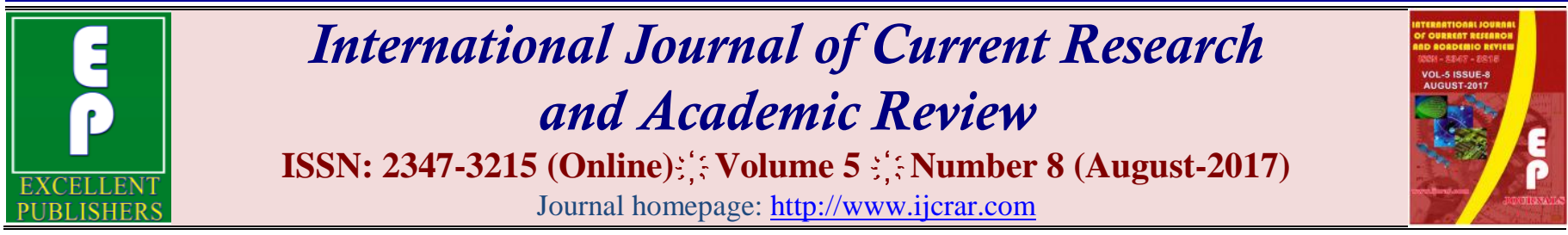

doi: https://doi.org/10.20546/ijcrar.2017.508.007

\title{
Psychosocial Determinants of Smoking among Adolescents in Al-Rifa'i City
}

\author{
Jaafar Sadiq Jaafar* \\ Arafat Hussain Al-Dujaili Asst. Prof. in psychiatry/University of Kufa/ Faculty of Medicine, Najaf, Iraq \\ *Corresponding author
}

\section{Abstract}

Smoking attends to kill one person every six seconds and causing a variety of diseases like cancer and even psychological problems and caused millions of mortalities. The adolescents are the most ages who start smoking due to many psychosocial factors they start smoking in early age causing more harms and addicted to smoking which worsen the psychological disorders. The study aim is to find the psychosocial determinants that cause smoking initiation and to find the relationship between these determinants and the demographic information. The study is a descriptive cross-sectional study applied on the mediatory and secondary smoking students in Al-Rifa $i$ City from the 1st November 2016 until $11^{\text {th }}$ Jun 2017 among (8) schools were chosen randomly and by using scales for depression, anxiety, stress and social determinants, and by using simple random sampling (370) smoking students were chosen whose ages were (13-19) years. (370) smoking students whose ages were (13-19) years, $(49.5 \%)$ of them had been assessed with mild depression, (47.3\%) of them had mild anxiety and (46.8\%) had a mild stress, in addition to (9) affected social factors. Moreover, there was a significant relationship between the depression and marital status, anxiety and each of marital status, parent social status, economic status, age of beginning of narghile smoking and the continuity of smoking, stress and smoking type and narghile smoking frequency, and the social determinants and the living status The general conclusion is that the psychological determinants (depression, anxiety, stress) and social determinants were affected in smoking initiation among adolescents and some of them having an advance situation of psychological problems. The study recommended working on establishing and improve programs to prevent smoking in schools in addition to working on teaching families and teachers how to deal with the psychological problems of the adolescents to not lose them in smoking way.
\end{abstract}

\section{Article Info}

Accepted: 30 July 2017

Available Online: 20 August 2017

\section{Keywords \\ Psychosocial, \\ Determinants, \\ Smoking, \\ Adolescents}

\section{Introduction}

World health organization stated that the smoking is a life threatening issue and every 6 seconds, someone dies because of smoking also tobacco smoking killed more than 100 million people around the world in the 20th century, and that is even more than all deaths of both World Wars, I and II together and deaths because of tobacco will be in numbers about one billion in the current century if current patterns of smoking move on.

Among adult and youth people, tobacco smoking is expected to be the main risk factor for the death of premature in men and in women will be the second most important risk factor and the main risk factor will be high blood pressure from 2010 to $2025^{(1)(2)}$. 
In addition, smoking is responsible for a variety problems and diseases as it is cleared and stated by United States Department of Health and Human Services that smoking causes many types of cancer ${ }^{(3)}$.

The interesting and dangerous point is that smoking among adolescents is an increasing problem world-wide, particularly in the developing countries ${ }^{(4)}$.

In fact, smoking tobacco in a younger age is considered to be a powerful predictor for using drugs and addict them in the future, actually among adolescence the tobacco is often the first drug used so we can call the smoking "gateway" towards unlawful drugs ${ }^{(5)}$.

Iraq is one of the developing countries which has this problem and it is beginning to be enormous by years. In 2013 the total income of the world's six largest companies of tobacco was 342 Billion dollars, and that is higher about $34 \%$ than the Gross National Income of Iraq, every year greater than 10,400 people in Iraq are killed by tobacco-caused disease, the percentage of death in 2010 was $9.1 \%$ of men and $5.6 \%$ of Women, while greater than 61,000 children and more than 3.6 million adults keep going to smoke in every single day ${ }^{(6)(1)}$.

The medical staff or health care professionals play a critical and vital role in preventing smoking among people and they clarify they warn them about the harmful effects of smoking, in addition, they are the model of health and how the healthy people should be. In addition, many studies had stated that the smokers quit smoking by listening to the advice of their doctors and health professionals or by the intervention programs of the health staff ${ }^{(7)(8)(9)}$.

Nurses are the biggest number of the health professionals in the world and the most intact healthcare provider with the people and patients and their interventions had helped many people to stop smoking, the nurses staff has many types of interventions ranging from a brief advice up to intensive programs to help in smoking cessation and many studies had stated these facts by numbers (10)(11)

\section{Objectives of the study}

1. To assess psychosocial determinants of cigarettes and narghile smoking among adolescents.

2. To find out the relationship between the psychosocial determinants and the adolescents' demographic data.

\section{Materials and Methods}

Study Design: A descriptive cross-sectional study design was carried out, so as to accomplish the stated objectives. During the period from 1st November 2016 to $11^{\text {th }}$ Jun 2017.

Study Setting: The study was conducted at mediatory and secondary schools (both governmental and privet) in Al-Rifa i City, Iraq. A total of the (8) mediatory and secondary schools selected randomly from a total of (14) mediatory and secondary schools existed in Al-Rifa $i$ City.

Study Sample: Information's that obtained from General Directorate for Education in the province of AlRifa' $i$ stated that there are (14) preparatory and secondary schools of boys existed in the Al-Rifa i city. After that, every school was represented by a number and then by using SPSS (SPSS $\rightarrow$ Data $\rightarrow$ Select cases) a simple random sample of (8) mediatory and secondary schools was the result, (2) privet secondary schools, (3) governmental mediatory schools and (3) secondary governmental schools. More than that, by using simple random sampling technique, (370) smoking students were selected randomly from above-mentioned schools.

The Instrument of the Study: By reviewing most of the related researches and studies, the questionnaire was prepared and modified depending on previous studies and it was divided into three main parts (part one contained sociodemographic information, part two the psychological part included scales about the depression, anxiety, and stress and part three which included questions about the social factors). The total number of questions for this tool was 53 questions (39 of questions for psychological determinants and 14 of questions for social factors).

\section{Results and Discussion}

Table (1) clarifies and shows the socio-demographic data of a total of (370) smoking adolescents who enrolled in the study, where most of them (80.5\%) were urban residency with mean age (16.8) as the high percentage was $(66.2 \%)$ for ages (17-19) years old, the majority of participants were single $(95.1 \%)$, living with their families $(99.7 \%)$, their father and mother live together (95.4), and their budget in Iraqi dinars is $<=10.000$ (76.8\%) with mean of (9407) thousand Iraqi dinars, furthermore the high percentage of the participants economic status was middle level (48.6\%), the majority 
of their father's education level was intermediate school graduated $(19.2 \%)$, and the majority of their mother's educational level was illiterate $(23.2 \%)$.

The table shows that the overall assessment of the social determinants of the adolescents smoking is affected $(82.7 \%)$. The previous table shows that there is a significant relationship between the depression and the marital status at p-value less than 0.05 , while there is a non-significant relationship with the other demographic data.

This table shows that there is a significant relationship between the anxiety and marital status, parent social status, economic status, age of beginning of narghile smoking and the continuity of smoking at p-value less than 0.05 , while there is a non-significant relationship with other demographic data.

The previous table shows that there is a significant relationship between stress and smoking type and narghile smoking frequency at p-value 0.05 , while there is a non- significant relationship with the other demographic data.

The table above summarizes and shows that the significant relationship is between the social determinants and the study subjects living at $p$-value 0.05 , while there is a non-relationship with the others demographic data.

\section{Part I: Socio-demographic data of the smoking adolescents}

The current study included a total number of (370) smoking adolescents who participate in this study, their mean age was 16.8 with the most group ages of the participant were (17-19) years, and this finding is similar to Karimy et al., 2013 study, it found that the mean age for participants is $16.49^{(12)}$ also Reda et al., 2012 did find the same result and his research stated that the mean age is 16.4 years ${ }^{(13)}$, in addition to that the most of the participants were living in urban areas and that the same finding result of Amin et al., 2011 found that the urban students were more the half of the participants ${ }^{(14)}$.

Moreover, the dominant marital status of the smoking adolescents was the single status Reda et al., 2012 had mentioned that in his study where the most of his participants were single ${ }^{(13)}$, that result was expected because of the nature of the Iraqi society and the age of the participants in this period of life it is usually to be single.

Parent social status of the participants were the father and mother living together and that was also expected because the nature of the Iraqi society that the family always lives together and the dominant relationship between father and mother is the marriage status, as the high percentage of the parent status was living together, the same result with Mays et al., 2014 they found that the majority parents living status of the participants still married and living together ${ }^{(15)}$, the vast majority of the adolescents living status was the living with parents the same finding by Al-Mohamed, and Amin, 2010 study they found that the smokers participants most of them are living with their parents ${ }^{(16)}$ and Gaffar et al., 2013 did find the same result ${ }^{(17)}$, such a result is normal to predict because of the nature of the Arabs countries society the whole family always still together especially when the younger members still not married they stay with the family.

Fig.1 Overall assessment of study sample for overall psychological determinants

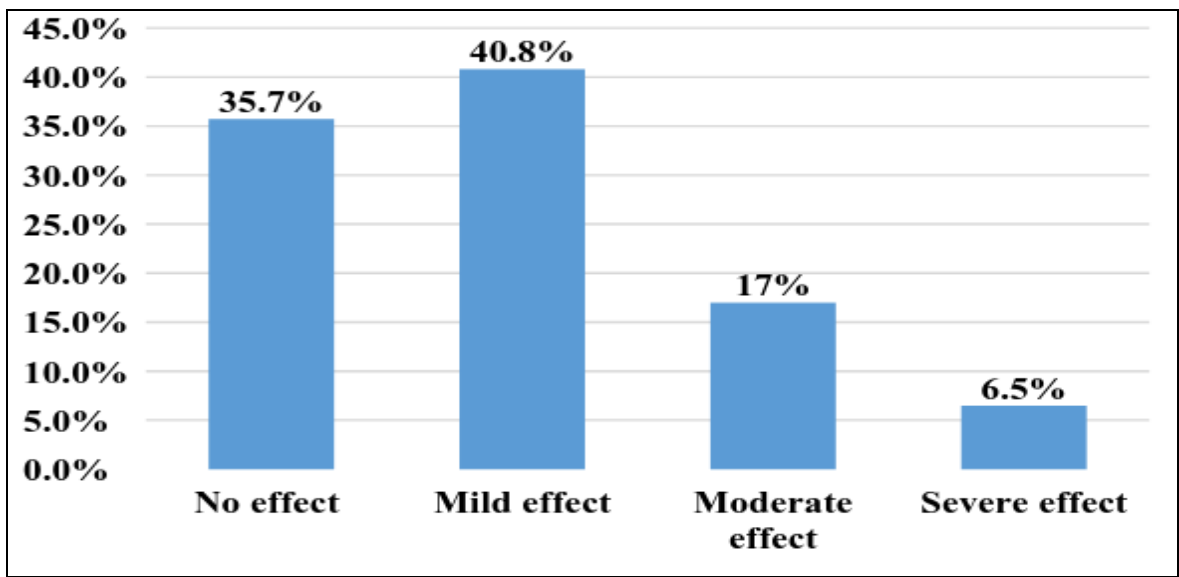


Table.1 The Socio-demographic characteristics and distribution of the study sample $(\mathrm{N}=370)$

\begin{tabular}{|c|c|c|c|}
\hline Demographic Data & Rating And Intervals & Frequency & Percent \\
\hline \multirow{2}{*}{ Residency } & Rural & 72 & 19.5 \\
\hline & Urban & 298 & 80.5 \\
\hline \multirow{3}{*}{ Age / years } & $13-16$ & 125 & 33.8 \\
\hline & $17-19$ & 245 & 66.2 \\
\hline & \multicolumn{3}{|c|}{ Mean (std. deviation) 16.8 (1.64) } \\
\hline \multirow{4}{*}{ Marital status } & Married & 15 & 4.1 \\
\hline & Single & 352 & 95.1 \\
\hline & Divorced & 1 & 0.3 \\
\hline & Widowed & 2 & 0.5 \\
\hline \multirow{4}{*}{ Parents' social status } & Living Together & 353 & 95.4 \\
\hline & Divorced & 2 & 0.5 \\
\hline & Separated & 4 & 1.1 \\
\hline & One Or Both Of Them Are Dead & 11 & 3 \\
\hline \multirow{2}{*}{ Living status } & With My Family & 369 & 99.7 \\
\hline & With my brother only & 1 & 0.3 \\
\hline \multirow{5}{*}{$\begin{array}{l}\text { Budget / Thousand } \\
\text { Iraqi Dinars }\end{array}$} & $<=10000$ & 284 & 76.8 \\
\hline & $11000-20000$ & 43 & 11.6 \\
\hline & $21000-30000$ & 39 & 10.5 \\
\hline & $31000+$ & 4 & 1.1 \\
\hline & \multicolumn{3}{|c|}{ Mean (std. deviation) 9407 (7.8) } \\
\hline \multirow{3}{*}{ Economic status } & Low level & 168 & 45.4 \\
\hline & Middle level & 180 & 48.6 \\
\hline & High level & 22 & 5.9 \\
\hline \multirow{8}{*}{$\begin{array}{c}\text { Father educational } \\
\text { level }\end{array}$} & Illiterate & 41 & 11.1 \\
\hline & Able To Read And Write & 57 & 15.4 \\
\hline & Primary School Graduated & 44 & 11.9 \\
\hline & Intermediate School Graduated & 71 & 19.2 \\
\hline & Secondary School Graduated & 37 & 10 \\
\hline & Institute Graduated & 47 & 12.7 \\
\hline & College Graduated & 49 & 13.2 \\
\hline & High Studied & 24 & 6.5 \\
\hline \multirow{8}{*}{$\begin{array}{c}\text { Mother educational } \\
\text { levels }\end{array}$} & Illiterate & 86 & 23.3 \\
\hline & Able To Read And Write & 76 & 20.5 \\
\hline & Primary School Graduated & 73 & 19.7 \\
\hline & Intermediate School Graduated & 50 & 13.5 \\
\hline & Secondary School Graduated & 21 & 5.7 \\
\hline & Institute Graduated & 23 & 6.2 \\
\hline & College Graduated & 28 & 7.6 \\
\hline & High Studied & 13 & 3.5 \\
\hline
\end{tabular}

Table.2 Overall assessment of study sample for social determinants

\begin{tabular}{|c|c|c|c|}
\hline Domain & Rating & Frequency & Percent \\
\hline \multirow{2}{*}{ Social determinants } & Affected & 306 & 82.7 \\
\cline { 2 - 4 } & Unaffected & 64 & 17.3 \\
\hline
\end{tabular}


Table.3 Relationship between the overall assessment of study sample for depression and their demographic and related data to smoking

\begin{tabular}{|c|c|c|c|}
\hline Demographic and data related to smoking & chi-square Value & df & p-value \\
\hline Residency & 1.464 & 3 & 0.691 \\
\hline Age & 1.258 & 3 & 0.739 \\
\hline Marital status & 21.972 & 9 & 0.009 \\
\hline Parents social status & 8.594 & 9 & 0.476 \\
\hline Living & 2.168 & 3 & 0.538 \\
\hline Budget & 8.370 & 9 & 0.497 \\
\hline Economic status & 5.084 & 6 & 0.533 \\
\hline Father education & 21.834 & 24 & 0.589 \\
\hline Mother education & 14.663 & 24 & 0.93 \\
\hline Knowledge & 2.035 & 3 & 0.565 \\
\hline Smoking type & 3.000 & 6 & 0.809 \\
\hline Age at the beginning of cigarettes smoking & 11.796 & 9 & 0.225 \\
\hline Age at the beginning of narghile smoking & 8.417 & 9 & 0.493 \\
\hline Cigarettes smoking frequency & 8.141 & 9 & 0.52 \\
\hline narghile smoking frequency & 4.835 & 9 & 0.848 \\
\hline Continuity & 4.187 & 3 & 0.242 \\
\hline Place of smoking & 6.420 & 12 & 0.893 \\
\hline Motives & 23.319 & 21 & 0.327 \\
\hline
\end{tabular}

Table.4 Relationship between the overall assessment of study sample for anxiety and their demographic and data related to smoking

\begin{tabular}{|c|c|c|c|}
\hline Demographic and data related to smoking & chi-square Value & df & p-value \\
\hline Residency & 0.145 & 2 & 0.93 \\
\hline Age & 1.124 & 2 & 0.57 \\
\hline Marital status & 31.919 & 6 & 0.001 \\
\hline Parents social status & 18.738 & 6 & 0.005 \\
\hline Living & 1.331 & 2 & 0.514 \\
\hline Budget & 1.167 & 6 & 0.979 \\
\hline Economic status & 19.057 & 4 & 0.001 \\
\hline Father education & 16.610 & 16 & 0.411 \\
\hline Mother education & 17.284 & 16 & 0.367 \\
\hline Knowledge & 0.720 & 2 & 0.698 \\
\hline Smoking type & 4.381 & 4 & 0.357 \\
\hline Age at the beginning of cigarettes smoking & 3.511 & 6 & 0.742 \\
\hline Age at the beginning of narghile smoking & 38.288 & 6 & 0.001 \\
\hline Cigarettes smoking frequency & 8.494 & 6 & 0.204 \\
\hline narghile smoking frequency & 7.804 & 6 & 0.253 \\
\hline Continuity & 10.035 & 2 & 0.007 \\
\hline Place of smoking & 10.549 & 8 & 0.229 \\
\hline Motives & 11.277 & 14 & 0.664 \\
\hline
\end{tabular}


Table.5 Relationship between the overall assessment of study sample for stress and their demographic and data related to smoking

\begin{tabular}{|c|c|c|c|}
\hline demographic and data related to smoking & chi-square Value & df & p-value \\
\hline Residency & 6.838 & 3 & 0.077 \\
\hline Age & 6.378 & 3 & 0.095 \\
\hline Marital status & 3.261 & 9 & 0.953 \\
\hline Parents social status & 3.396 & 9 & 0.947 \\
\hline Living & 4.794 & 3 & 0.188 \\
\hline Budget & 8.300 & 9 & 0.504 \\
\hline Economic status & 3.283 & 6 & 0.773 \\
\hline Father education & 19.596 & 24 & 0.72 \\
\hline Mother education & 28.230 & 24 & 0.25 \\
\hline Knowledge & 1.746 & 3 & 0.627 \\
\hline Smoking type & 15.804 & 6 & 0.015 \\
\hline Age at the beginning of cigarettes smoking & 11.476 & 9 & 0.244 \\
\hline Age at the beginning of narghile smoking & 12.916 & 9 & 0.166 \\
\hline Cigarettes smoking frequency & 7.293 & 9 & 0.607 \\
\hline narghile smoking frequency & 29.451 & 9 & 0.001 \\
\hline Continuity & 4.384 & 3 & 0.223 \\
\hline Place of smoking & 10.022 & 12 & 0.614 \\
\hline Motives & 11.826 & 21 & 0.944 \\
\hline
\end{tabular}

Table.6 Relationship between the overall assessment of study sample for stress and their demographic and data related to smoking

\begin{tabular}{|c|c|c|c|}
\hline demographic and data related to smoking & chi-square Value & df & p-value \\
\hline Residency & 6.838 & 3 & 0.077 \\
\hline Age & 6.378 & 3 & 0.095 \\
\hline Marital status & 3.261 & 9 & 0.953 \\
\hline Parents social status & 3.396 & 9 & 0.947 \\
\hline Living & 4.794 & 3 & 0.188 \\
\hline Budget & 8.300 & 9 & 0.504 \\
\hline Economic status & 3.283 & 6 & 0.773 \\
\hline Father education & 19.596 & 24 & 0.72 \\
\hline Mother education & 28.230 & 24 & 0.25 \\
\hline Knowledge & 1.746 & 3 & 0.627 \\
\hline Smoking type & 15.804 & 6 & 0.015 \\
\hline Age at the beginning of cigarettes smoking & 11.476 & 9 & 0.244 \\
\hline Age at the beginning of narghile smoking & 12.916 & 9 & 0.166 \\
\hline Cigarettes smoking frequency & 7.293 & 9 & 0.607 \\
\hline narghile smoking frequency & 29.451 & 9 & 0.001 \\
\hline Continuity & 4.384 & 3 & 0.223 \\
\hline Place of smoking & 10.022 & 12 & 0.614 \\
\hline Motives & 11.826 & 21 & 0.944 \\
\hline
\end{tabular}


The economic status of the smoking adolescents was almost equal between low status and middle status but the last one was slightly more than the other where the middle was $(48.6 \%)$ while low was $(45.4 \%)$ and that explains the other findings of the budget quantity per week where less or equal to ten thousand Iraqi dinars. The budget of the majority of the participants and the average was about ten thousand, this result does not agree with Siziya et al., 2007 their study stated high level of the participants and the pocket money were higher because of the economic status of the Kurdistan region is better and higher and the income of each citizen is higher than the other Iraqi regions ${ }^{(18)}$. Moreover, the educational level of the parents for the most of the participants for father was intermediate school graduated and for mothers the highest percentage of educational mothers' level is illiterate same result with Amin et al., 2012, they find the same result about the educational level for majority of fathers participants which was intermediate and for mothers was illiterate ${ }^{(19)}$.

\section{Part II: The psychological determinants of the smoking adolescents}

\section{Assessment of the depression}

According to the depression scale and all the (9) questions, the diagnoses was mild depression for the majority of the participants and each question alone the diagnosis was mild too.

Same assessment by Amin et al., 2012 who assessed his smoking participants' teenagers by mild or minor depression for the most of them ${ }^{(19)}$.

\section{Assessment of the anxiety status}

In the result of the anxiety scale of (20) questions for each question, the assessment of the anxiety status of the smoking adolescents was mild except for the questions (1 and 20) and the overall assessment was mild anxiety status for the most of smokers in our study.

Amin et al., 2012 agreed with this result, he had assessed his participant for anxiety and he found out that the most proportion of them are with mild anxiety ${ }^{(19)}$.

\section{Assessment of the stress}

Ten questions in stress scale assessed the stress status of the smoking teenagers which was mild for both general assessment and each question alone.
The previous assessment is agreed with Mason et al., 2015 study who assessed that the major of his sample was with mild stress ${ }^{(20)}$.

Part III: The relationships between the social determinants and the smoking among adolescents

The only significant relationship was between the social determinants and the study subjects living status at pvalue (0.05). This result was because the vast majority of the participants were living with their parents so it was predicted to be a significant relationship.

\section{References}

Abdulateef, D. S., Ali, A. J., Abdulateef, D. S. \& Mohesh, M. I. G. Smoking Knowledge, Attitude, and Practices among Health Care Professionals from Sulaymaniyah City/Iraq. Tob. Use Insights 9, 1-6 (2016).

Al-Mohamed, H. I. \& Amin, T. T. Pattern and prevalence of smoking among students at King Faisal University, Al Hassa, Saudi Arabia. East. Mediterr. Heal. J. 16, 56-64 (2010).

Amin, T. T., Amr, M. A. M., Zaza Omar, B. \& Amin, T. T. Psychosocial predictors of smoking among secondary school students in Al-Hassa, Saudi Arabia. J. Behav. Med. 34, 339-350 (2011).

Amin, T. T., Amr, M. A. M., Zaza, B. O. \& Kaliyadan, F. Predictors of waterpipe smoking among secondary school adolescents in al Hassa, Saudi Arabia. Int. J. Behav. Med. 19, 324-335 (2012).

Bagchi, N. N., Ganguly, S., Pal, S. \& Chatterjee, S. A study on smoking and associated psychosocial factors among adolescent students in Kolkata, India. Indian J Public Heal. 58, 50-53 (2014).

Eriksen, M., Mackay, J., Schluger, N., Gomeshtapeh, F. I. \& Drope, J. The Tobacoo Atlas. (American Cancer Society, 2015).

Gaffar, A. M., Alsanosy, R. M., Mahfouz, M. S. \& Mutwakel, A. Sociodemographic factors associated with tobacco smoking among intermediate and secondary school students in jazan region of Saudi Arabia. Subst. Abus. 34, 381-8 (2013).

Huizink, A. C., et al., Tobacco, cannabis, and other illicit drug use among Finnish adolescent twins: causal relationship or correlated liabilities? J. Stud. Alcohol Drugs 71, 5-14 (2010).

International Monetary Fund. World Economic Outlook: Uneven Growth Short- and Long-Term Factors. World Economic and Financial Surveys (2015). doi:10.1163/187502311797543854 
Karimy, M., Niknami, S., Heidarnia, A. R., Hajizadeh, I. \& Montazeri, A. Prevalence and determinants of male adolescents' smoking in Iran: An explanation based on the theory of planned behavior. Iran. Red Crescent Med. J. 15, 187-193 (2013).

Mahapatra, S., Kamath, R., Shetty, B. \& Binu, V. Risk of oral cancer associated with gutka and other tobacco products: A hospital-based case-control study. $J$. Cancer Res. Ther. 11, 199-203 (2015).

Mansour, A. Y. Predictors of Smoking among Saudi Dental Students in Jeddah. 41, 329-337 (2017).

Mason, M., et al., Time-varying effects of a text-based smoking cessation intervention for urban adolescents. Drug Alcohol Depend. 157, 99-105 (2015).

Mays, D., et al., Influences of tobacco advertising exposure and conduct problems on smoking behaviors among adolescent males and females. Nicotine Tob. Res. 16, 855-863 (2014).

Reda, A. A., Moges, A., Yazew, B. \& Biadgilign, S. Determinants of cigarette smoking among school adolescents in eastern Ethiopia: a cross-sectional study. Harm Reduct. J. 9, 39 (2012).

\section{How to cite this article:}

Jaafar Sadiq Jaafar. 2017. Psychosocial Determinants of Smoking among Adolescents in Al-Rifa'i City. Int.J.Curr.Res.Aca.Rev. 5(8), 43-50. doi: https://doi.org/10.20546/ijcrar.2017.508.007
Rice, V. H., \& Stead, L. F. Nursing interventions for smoking cessation (Review). Cochrane. Database. Syst. Rev. CD001188- (2013). doi:10.1002/14651858.CD001188.pub4.www.cochr anelibrary.com

Sarna, L., et al., Evaluation of a web-based educational programme on changes in frequency of nurses' interventions to help smokers quit and reduce second-hand smoke exposure in China. J. Adv. Nurs. 72, 118-126 (2015).

SHAIK, S. S., DOSHI, D., BANDARI, S. R., MADUPU, P. R. \& KULKARNI, S. Tobacco Use Cessation and Prevention - A Review. J. Clin. Diagnostic Res. 10, 13-17 (2016).

Siziya, S., Muula, A. S. \& Rudatsikira, E. Correlates of current cigarette smoking among in-school adolescents in the Kurdistan region of Iraq. Confl. Health 1, 13 (2007).

United States Department of Health and Human Services. The Health Consequences of Smoking - 50 Years of Progress A Report of the Surgeon General. A Report of the Surgeon General (2014). 